\title{
Relationship between press freedom and human development: Evidence from Eastern African countries
}

\author{
Abraham Ejigu \\ Amanuel Gebru ${ }^{1}$ \\ Addis Ababa University, Ethiopia
}

DOI: 10.30547/worldofmedia.1.2020.1

\begin{abstract}
The objective of the study was to establish a nexus between the three dimensions of press freedom (economic, political and legal environments) and human development by taking five-year longitudinal data pertaining to six Eastern African countries: Eritrea, Ethiopia, Djibouti, Kenya, Sudan, and Uganda. The interrogation is theoretically informed by Amartya Sen's Capability Approach which forms the conceptual foundation for the operationalization of the Human Development Index. The empirical examination of the association among the variables of interest employed both correlation and multiple panel linear regression analysis methods. Prior to the analysis, a protocol was followed that included preliminary tests of statistical assumptions underlying the use of the methods to ensure that the statistical chemistry of the data was suitable to the methods selected. The preliminary tests provided evidence that the data was indeed appropriate for the methods selected. Subsequent multiple regression tests indicated that both the political $(p=.000)$ and economic $(p=.008)$ dimensions of press freedom are important predictors of human development in the Eastern Africa region, lending support to the extant literature. However, the legal environment investigation of the role of press legislation failed to qualify as an explanatory variable $(\mathrm{p}=.071)$. Recommendations for further research are presented based on the limitations noted.
\end{abstract}

\section{Keywords}

Press freedom, political environment, economic environment, legal environment, regression, estimation, model.

\footnotetext{
${ }^{1}$ Corresponding author:

Amanuel Gebru, Addis Ababa University, NBH1, 4killo King George VI St, Addis Ababa, Ethiopia.

Email: amanuel.gebru@aau.edu.et
} 


\section{Introduction}

Press freedom is the communication right to self-expression through a variety of modalities in full freedom and independence based on constitutional and legal provisions as may be enjoyed by professional journalists or non-journalists. Press freedom has been historically based on American conceptions of liberal media ecosystems characterized by freedom of competition, diversity, independence and openness and absence of regulatory inhibitions (Merrill, 2000). In recent years the key construct of freedom of the press and its association with human development has attracted growing scholarly attention. Indeed, the idea of a free press has considerable intuitive appeal and rhetorical force as a desideratum for development as it represents a climate of enabling freedom for information generation, dissemination and utilization as an input for advances in human development endeavors in a wide variety of dimensions. Press freedom is a dynamic concept and its horizon has widened following massive technological developments that have inevitably transformed the communication realities of the contemporary world. Therefore, freedoms now necessarily include digital liberties in the receptive and expressive realms.

Human development itself is an important construct which pertains to freedom granted to citizens to take the life courses of their choosing, and to strive freely in their legitimate life pursuits of growth and development as they struggle to prevail over life's constraints. It is a reference to life paths being open and the possibility of reaching goals being left to the individual (UNDP, 1990). Human development is multidimensional as it encompasses resources, capabilities and functions-representing a broader framework of conception of freedoms. Human development is generally assessed by the Human Development Index, which takes into stock: life expectancy; literacy rates; access to education; gross domestic product (GDP) per capita, operationalized as buying power (UNESCO, 2010).

There is a growing body of literature discussing the global association between freedom of the press as a desirable catalyst and the human development level. Indeed, the idea of a free press has a lot of intuitive appeal as a desideratum for development as it represents a climate of freedom for information generation, dissemination and utilization as an input for advances of human development endeavors in a wide variety of dimensions. Freedom also represents enabling conditions for the best ideas to emerge in the market that can then be utilized in the service of humanity and its progress and betterment.

However, the link between press freedom and human development is not unequivocally straightforward and conclusive casualty, or correlation, has not 
been established (Gunaratne, 2002). The absence of a universal, definitive empirical nexus is compounded by definitional imprecision of the constructs involved in econometric regression, not to mention the numerous mediating or moderating factors. It is also further compounded by the plethora of variables of relevance and contextual idiosyncrasies that are cultural, ideological or geographical. On the whole, while there is some literature analyzing the association between the freedom of the press and human development and its dimensions (Alam \& Shah, 2013), there is still a need for more work involving specific contexts. In fact, there has been a research call for a closer look at the picture examining poor countries as empirical inputs or countries that tend to appear to be a degree different (Burrowes, 1997; Gunaratne, 2002; Islam \& Osmani, 2017; Rogers, 1997).The Eastern African countries seem to fit with such categorization. Thus, take Eritrea and its dire state of the media as consistently confirmed by global reports, Ethiopia as a World Bank acclaimed developing nation, despite a government dominated media sector and a weak legal environment coupled with recurrent and often spiraling ethnic unrest, Kenya as a nation with a tradition of vibrant press, and Uganda, Sudan, and Djibouti with their own specific features of relevance in regard to the more descriptive, expository, classificatory and analytical legal, political and economic environments. The kaleidoscope of countries in Eastern Africa region call attention to investigation along the lines of the recommendations for study of a peripheral assemblage of states. Therefore, this study aims at establishing the relationship between press freedom and human development with a particular focus on Eastern African countries. Assisted by the extant literature, this study sets out to test the hypothesized relationships between the three press freedom dimensions (economic environment, political environment and legal environment) and human development in the region of study.

In this study the following hypotheses will be tested:

$\mathrm{H1}$ : There is a significant relationship between the legal environment (one of the Press Freedom indices) and human development of Eastern African countries.

$\mathrm{H} 2$ : There is a significant relationship between the political environment (one of the Press Freedom indices) and human development of Eastern African countries.

H3: There is a significant relationship between the economic environment (one of the Press Freedom indices) and human development of Eastern African countries. 


\section{Theoretical framework and related literature}

Considering its potential scholars have proposed the use of Amartya Sen's capability approach as a framework for studies in communication for development and social transformation (Jacobson, 2016). The approach has advantages over modernization theory now largely discredited for its linear and oversimplified conceptions of the complexities of development as well as its undue focus on the cultural factor based on its Eurocentric blindfolds (Matunhu, 2011). The core of the line of thinking is that freedom is an enabler of multiple development outcomes. Thus, political (including media and communication) freedoms would have a ripple effect as they would lead to further yields in terms of socio-political betterment. The model addresses in the main the capability framework.

Core concepts in the framework are functionings and capabilities. Functionings are expressed in a binary of 'beings and doings' (Sen, 1999). Functionings address a multiplicity of states of being expressed in such examples as being free, content, frustrated, or informed, connected, left out, etc. Functionings can also mean communicating, sending, posting, protesting, voting, commenting etc. (Fleurbaey, 2002; Kaufman, 2006a).

On the other hand, capabilities refer to liberties that enable performance such as a constitutional framework permitting free self-expression, or a forum to express a political opinion in mediated ways or in person extending the broad framework of life freedoms and choices (Sen, 1999). Thus, while the functionings refer to ends, capabilities address the question of the means. The means and ends are tied by the 'conversion factor'. 'Capability' in context would not solely refer to a citizen's expressive abilities per se but to a receptive or expressive communication opportunity made available through a negotiation of intra-personal and contextual conversion protocols (Robeyns, 2005).

The conversion is important as media structures or media freedom legislation alone is not enough. A free press must be in place for a free flow of ideas from which society can choose the ones with the highest utility and rationality .While in the human development project ' ... political freedoms and liberties are permissive advantages, their effectiveness would depend on the how they are exercised' (Sen, 1999).

Together these serve to illuminate the press freedom-human development nexus. They are related to information choices available and freedoms of informational access in a national political landscape. The basic tenet is that media and information freedoms help in terms of actualizing human development as expressed in the amount and quality of freedoms available to citizenry. This 
postulate further raises the issue of how information and communication freedoms in a polity contribute to human development aspirations (Foster \& Handy, 2008) which again leads to the thesis of a media freedom - human development nexus.

\section{Press freedom and human development}

Freedom of the press is not a straightforward construct and the definitions do not necessarily converge fully. Yet there appears to be a common denominator in most definitions of the term. For the most part, the definitions involve removing the 'restraints' and the 'role' of the freedom of the press. Nevertheless, many of the popular definitions of the freedom of the press differ in specifying the source of restraints. Asante (1997) suggests that any serious discussion concerning the conceptual definition of the freedom of the press must include economic, social, cultural, managerial, and political factors. This means enabling contexts should be there for the press to operate freely from political, financial and other pressures. This freedom mainly relates to the absence of government and political restraints (Hachten, 2005).

Further, Hachten (2005) maintains that the role of the freedom of the press is something more. He defines the freedom of the press as 'the right of the press to report, to comment on, and to criticize its own government without retaliation or threat of retaliation from the authority', which he calls 'the right to talk politics' (Hachten, 2005). He asserts that this type of free and independent press only exists in the Western countries that have the following characteristics: laws protecting civil liberties and property, high income per capita, highly educated citizenry, possession of opposing political parties, financial support of the news media, and established independent journalism (Hachten, 2005). However, Gunaratne (2005) criticized Hachten's definition of the freedom of the press noting that it only examines the Euro-American (nation-state level) experience and ignores the center-dominated world-system level where government and media operate the system of communication outlets.

Dennis and Merrill (1996) focus on the role of promotion and education in relation to the freedom of the press. They define the freedom of the press as 'the right to communicate ideas, opinions, and information through the printed word without government restraint', and state that the main purpose of the freedom of the press 'is to promote and educate an informed electorate that can make decisions about public affairs'. Both authors agree that there is no existence of an absolute press freedom, but they disagree in regard to whether the press in the USA is free or not. Dennis claims there is no free press in the USA, 
and free press is a dream that can hardly be achieved because of the interaction between the interrelated system of rights, principles, practices, and institutions. On the other hand, Merrill disagrees with Dennis believing the press in the U.S. is relatively free in regard to other countries because it has fewer government restraints (Dennis \& Merrill, 1996).

On the other hand, Weaver (1977) builds upon Dennis and Merrill's argument stating that an adequate account of the freedom of the press must include all 'other restraints'. He explains that the arguments of free press revolve around two main questions: 1) what is it? and, 2) How much can it be? He defines the freedom of the press as: 1 ) the relative absence of governmental restraints on the media; 2) the relative absence of governmental and all other restraints on the media; and, 3) not only the absence of restraints on mass media, but also the presence of those conditions necessary to ensure the dissemination of a diversity of ideas and opinions to a relatively large audience, like an enforced right of access to newspapers and radio stations (Weaver, 1977). Other scholars define the freedom of the press from the perspective of its functionality in society. For instance, Nam and Oh (1973) define the freedom of the press as an independent adversary with no fear of arbitrary sanction and free to criticize the policies and personnel of the power elite. Writing from a modern and classical point of view, Kelley and Donway (1990) believe that free press means performing the monitorial function of preventing the state from abusing the rights of its citizens. Put differently, Kelley and Donway seem to suggest that an adequate definition of the freedom of the press should involve the presses' ability to keep a government in check. The differences noted in the definitional and conceptual literature have implications for the evaluation of press freedom.

Although the figure of global institutions measuring press freedom is in excess of 100 (Becker et al., 2007), currently there are four most prominent organizations differently but fairly convergently measuring the freedom of the press internationally: Freedom House, Reporters Without Borders, International Research and Exchanges Board (IREX), and the Committee to Protect Journalists (CPJ), but the first two institutions are the most widely recognized (Abdulsamad, 2008). Since 1980, Freedom House has been collecting data on the freedom of the press around the world. The survey instrument that Freedom House uses (Freedom House Survey) considers analytical reports of regional experts and scholars, as well as numerical ratings for 197 countries and territories on a scale of 0 to 100 with 0 as the highest degree of freedom of the press and 100 as the lowest degree. Based on 23 methodology questions, the survey groups the countries into three categories: 'Free' scoring 0 to 30; 'Partly Free' scoring 31 
to 60; and 'Not Free' scoring 61 to 100. The Freedom House Survey uses three broad analytical areas: 1) the legal environment (laws and regulations), which is worth 30 points; 2) the political environment (political control or pressure over the content), worth 40 points; 3 ) the economic environment (structure of ownership and the effect of corruption on content) that is worth 30 points.

The research and ratings process involves more than 60 analysts, including members of the core research team headquartered in New York along with outside consultants, who prepare the draft ratings and country reports (Freedom House, 2014). The conclusions are reached after gathering information from professional contacts in a variety of countries, staff and consultant travel, international visitors, the findings of human rights and press freedom organizations, specialists in geographic and geopolitical areas, the reports of governments and multilateral bodies, and a variety of domestic and international news media.

The ratings are reviewed individually and on a comparative basis in a set of six regional meetings involving analysts, advisers, and Freedom House staff. The ratings are compared with the previous year's findings, and any major proposed numerical shifts or category changes are subjected to more intensive scrutiny. These reviews are followed by cross-regional assessments in which efforts are made to ensure comparability and consistency in the findings (Freedom House, 2014).

The diverse nature of the methodological questions encompasses the varied ways in which pressure can be placed upon the flow of information and the ability of print, broadcast, and internet-based media and journalists to operate freely and without fear of repercussions. In short, the institution seeks to provide a picture of the entire 'enabling environment' in which the media in each country operates. It seeks to assess the degree of news and information diversity available to the public in any given country, from either local or transnational sources (Freedom House, 2014).

The legal environment (legenv) category encompasses an examination of both the laws and regulations that could influence media content and the government's inclination to use these laws and legal institutions to restrict the media's ability to operate. It assesses the positive impact of legal and constitutional guarantees for freedom of expression; the potentially negative aspects of security legislation, the penal code, and other criminal statutes; penalties for libel and defamation; the existence of and ability to use freedom of information legislation; the independence of the judiciary and of official media regulatory bodies; registration requirements for both media outlets and journalists; and the ability of journalists' groups to operate freely. 
Under the political environment (polienv) category is the ability to evaluate the degree of political control over the content of the news media. Issues examined include the editorial independence of both state-owned and privately owned outlets; access to information and sources; official censorship and selfcensorship; the vibrancy of the media and the diversity of news available within each country; the ability of both foreign and local reporters to cover the news freely and without harassment; and the intimidation of journalists or bloggers by the state or other actors including arbitrary detention and imprisonment, violent assaults, and other threats.

The category that examines the economic environment (econenv) for the media includes the structure of media ownership; transparency and concentration of ownership; the costs of establishing media as well as any impediments to news production and distribution; the selective withholding of advertising or subsidies by the state or other actors; the impact of corruption and bribery on content; and the extent to which the economic situation in a country impacts the development and sustainability of the media. In other words, it relates to issues of media economics. However, the most commonly used measure comes from Freedom House, but there are other measures evaluating the same but variously understood construct. The extant four measures come from Freedom House, Reporters Sans Frontières (Reporters without Borders), the International Research and Exchanges Board (IREX), and the Committee to Protect Journalists (CPJ). However, they tend to have convergent validity (Becker et al., 2007).

\section{Human development and the Human Development Index}

Human development has attracted scholarly attention as a construct of diverse views that have evolved over time. Traditional conceptions of development were economic and financial parameters, but more recent thinking has broadened to focus on the freedoms enjoyed by ordinary people in reference to how much control they have over their life choices (Streeten, 1994). The expansion of locus of control would mean that people have fewer frustrations in the matter of realizing their aspirations expressed in what they are able to do or become. The freedom and actual possibility to reach the top of their hierarch of needs probably explains the core thoughts of Amartya Sen. According to the UN human development is 'the process of enlarging people's choices' to help them 'lead a long and healthy life, to be educated, to enjoy a decent standard of living', as well as 'political freedom, other guaranteed human rights and various ingredients of self-respect' (UN, 1997). These include communication rights and freedoms. 
While numerous indices have been developed to measure human development perhaps the most common is the Human Development Index. The index is based on the capabilities approach as a measure of well-being expressed in people's freedom and choices and actual realization of their potential. This measure has broadened economic metrics as measures of human development from the narrow economic perspective. It addresses the fullness of the human condition including the right to civic and life satisfaction (Gasper, 2014). The index is important to show countries where they stand in terms of addressing the wellbeing of their people, not just in matters of earnings. An important communication relevant aspect of measuring human development is human rights in connection with receptive and expressive communication rights and opportunities. This makes the press freedom-human development nexus more logically grounded.

\section{Research methodology}

The primary aim of this study is to examine the relationship between press freedom and human development in Eastern African countries. To achieve this objective, an explanatory type of research design was employed. The explanatory type of research design helps to identify and evaluate the causal relationships between variables under consideration, i.e. the explanatory research design is employed to examine the relationship of the stated variables.

Data. The necessary data for this study were collected from secondary sources that included press freedom indices from Freedom House and Human Development Index from UNDP over a period of five years (2011-2015) and presented in Tables 3 and 4.

Sample design. The population of the study is Eastern African countries. Countries located in Eastern Africa are included purposively. Thus, the following six countries were taken for the population. However, Somalia was removed from the population due to data insufficiency. Therefore, the sampled countries include Ethiopia, Eritrea, Djibouti, Sudan, Kenya and Uganda.

Description of variables and measurements. In this study, the independent variables are components of the Press Freedom Index and the dependent variable is the Human Development Index of the selected countries.

Independent variables. As used in this study, the Freedom House Index refers to three criteria for evaluating press freedom in 197 countries across the world: legal environment (examination of laws and regulations that could influence media content but also the government's inclination to use those laws to restrict the media's ability to operate), political influence (degree of political control over information) and economic pressures (economic barriers to entry 
to the media sector, and impact of corruption). The index score allotted to a country ranges from 0 to 100 depending on the extent of the constraints on press freedom. A score of between 0 and 30 indicates that the press is free; a score of between 31 and 60 indicates that it is only partly free and a score above 61 means that it is not free.

Dependent variables. The dependent variable is human development which is measured by the Human Development Index composition of education, life expectancy at birth, and gross national income per capita of countries.

Specifications of the empirical research model. To estimate the impact of press freedom on human development in Eastern African countries, the following general empirical research model was developed.

Where:

$$
\text { Yit }=\beta 0+\Sigma \beta K X i t+\varepsilon i t
$$

- Yit represents the dependent variable, Human Development Index (HDI) of countries $i$ for time period $t$.

- $\quad \beta 0$ is the intercept.

- $\beta K$ represents the coefficients of the Xit variables.

- Xit represents the explanatory variables, press freedom indices like legal environment (LE), political environment (PE) and economic environment (EE) of country $i$ for time period $t$.

- $\quad$ eit is the error term.

- The above general empirical research model is changed into the study variables to find out the relationship of human development and press freedom as follows:

$$
\text { HDIit }=\beta 0+\beta 1(\text { LEit })+\beta 2(\text { PEit })+\beta 3(\text { EEit })+\varepsilon
$$

\section{Methods of data analysis}

To analyze the collected data, descriptive, correlation and multiple panel linear regression data analysis methods were employed. The descriptive statistics is used to quantitatively describe the important features of the variables using mean, maximum, minimum and standard deviations. The correlation analysis is used to identify the relationships between the independent and dependent variables using Pearson correlation analysis. Multiple panel linear regression analysis is used to test the hypothesis and to explain the relationship between the human development indices and the Press Freedom Index. SPPS 23 version software was used for the analysis. 


\section{Results and discussion}

This section presents the descriptive statistics, correlation analysis and multiple panel linear regression results of the study's variables presented sequentially.

Below, a statistics summary of each variable in the study is presented. The variables include both predictor and outcome variables. The outcome variable is used in order to measure the Eastern African countries' Human Development Index (HDI), whereas the predictor variables are measures of the countries' economic, legal and political environment components of the Press Freedom Index during the year. Accordingly, the descriptive statistics for all variables are presented below in Table 1.

Table 1

Descriptive statistics of the study variables

\begin{tabular}{|c|c|c|c|c|c|}
\hline variables & Mean & Maximum & Minimum & Std.Dev. & observation \\
\hline HDI & .464 & .548 & .386 & .0474 & 30 \\
\hline Econenv & 19.4333 & 24.00 & 14.00 & 3.60730 & 30 \\
\hline Legenv & 23.9333 & 30.00 & 16.00 & 4.70461 & 30 \\
\hline Polienv & 29.5333 & 40.00 & 18.00 & 6.96659 & 30 \\
\hline
\end{tabular}

Source: SPSS Summary statistics result based on secondary data

As presented in Table 1, the average value of the Human Development Index for the sampled Eastern African countries is 46.4 percent (mean=0.464) with a maximum value of .54 which represents the Kenyan human development index and the minimum value of .38 of Eritrea's Human Development Index respectively. As indicated in the above table, the standard deviation is .0474 which is below one which gives an indication that the values of Eastern African countries' Human Development indices are close to each other and vary from the average value insignificantly as indicated in the table. In other words, the education, life expectancy and gross national income per capita of these countries do not differ significantly as is evident in the values between .54 and .38.

It is confirmed in Table 1 that the average value of the economic environment for the sampled Eastern African countries is 19 (mean $=19.43$ ) with a maximum of 24 (Eritrea) and a minimum of 14 (Uganda). The standard deviation indicates that for the sampled Eastern African countries, the economic environment deviates by 3.6 from the average value of 19.43 . Since the standard deviation is above one, it indicates that there is a wide dispersion in the economic environment value of the sampled Eastern African countries. 
This seems to show that the structure of media ownership; transparency and concentration of ownership; the costs of establishing media as well as any impediments to news production and distribution, the corruption and bribery impinging on content; and the character of the economic situation are significantly different among the countries of the region.

The average value for the legal environment of the sampled Eastern African countries is 23.9 with a maximum of 30 , which represents Eritrea and 16, which is the value for Kenya. The standard deviation of the legal environment construct is 4.7. As the value is above one, it suggests that the sampled Eastern African countries have dispersed values which deviate from the mean value. This disparity can be explained by the presence of laws and regulations that could influence media content as represented by a significant degree of dispersion of units between 30 and 16. This seems to suggest that there are laws and legal institutions that stand in the way of a more liberal media operation in the studied countries.

It is also shown that the mean value for the political environment of the sampled Eastern African countries is 29.53 with the Eritrean maximum value of 40 and the Kenyan minimum value of 18 . The standard deviation of the construct of the political environment is 6.9 implying significant disparity among the sampled countries as may be exemplified by the free and vibrant press in Kenya and the obstructive media climate in Eritrea. The range of values shows that there was a high tendency of political control over the content of the news media in these countries during the study period. The political spectrum showed government actions were characterised by a propensity to thwart media freedoms and institutions.

Further, to identify the relationship among the variables of press freedom and human development, the Pearson's correlation coefficient was used (See Table 2) The correlation coefficients show the extent and direction of the linear relationship between press freedom variables and human development indicators of the sampled Eastern African countries. The correlation analysis shows the association between the Human Development Index and press freedom variables. The probability is shown in parenthesis along with the Pearson's R for the correlation matrix in Table 2. The significance level is also shown as ***, ** and * for $1 \%, 5 \%$ and $10 \%$ levels respectively. In line with statistical protocols, the correlation coefficients are diagnosed for the presence of high collinearity among regressors. Since the correlation analysis shows only the degree of association, it is followed by a multiple regression analysis in search of explanatory significance. 
In Table 2, the correlation matrix shows the relationship of the Human Development Index with the economic, legal and political environments.

Table 2

Correlation analysis of Human Development Index and Press Freedom Indices

\begin{tabular}{|c|c|c|c|c|}
\hline & HDI & Econenv & Legenv & Polienv \\
\hline HDI & 1 & & & \\
\hline Econenv & $\begin{array}{c}.068 \\
0.723\end{array}$ & 1 & & \\
\hline Legenv & $\begin{array}{c}-.484^{* *} \\
.007\end{array}$ & $\begin{array}{c}.6813^{* *} \\
.000\end{array}$ & 1 & \\
\hline Polienv & $-0.624^{* *}$ & $.530^{* *}$ & $.959^{* * *}$ & 1 \\
\hline & .000 & .003 & .000 & \\
\hline
\end{tabular}

Source: SPSS correlation result based on the data obtained from secondary data.

* Correlation is significant at the 0.05 level (2-tailed).

** Correlation is significant at the 0.01 level (2-tailed)

Table 2 portrays that the legal and political environments are negatively and significantly correlated at a 1 percent significance level with the Human Development Index.

On the other hand, the economic environment shows a positive correlation to the Human Development Index.

Based on the relevant Press Freedom and Human Development Indices figures reported in Tables 3 and 4, the Pearson correlation coefficients of the economic, legal and political environments are 6.8 percent, -48.4 percent and -62.4 percent respectively. From this, it can be understood that the economic environment has no strong association with the Human Development Index whereas the legal and political environments have a strong negative association with the Human Development Index. This may be in part a case of spurious association.

Further, the correlation analysis shows only the direction and degree of association between variables, and it does not permit causal inferences regarding the relationship between the identified variables. Thus, we turn to a regression analysis to overcome the shortcomings of the correlation analysis.

A linear regression model was fitted to examine the impact of press freedom variables on the sampled Eastern African countries' Human Development Index. 
The method of least squares has some very attractive statistical properties that have made it one of the most powerful and popular methods of regression analysis (Gujarati, 2004). Thus, to conduct the appropriate diagnosis tests, the ordinary least squares (OLS) estimation method was used.

Preliminary tests of the data set. Before running the model, the data sets were tested for the classical linear regression model assumptions. The following critical assumptions must be met before utilizing the OLS estimation in order to test validly the hypothesis and estimate the coefficient (Hoffmann, 2010). The classical linear regression model assumptions and their diagnostic tests are discussed below.

The average value of the errors is zero. If a constant term is included in the regression equation, this assumption will never be violated. In this study, this assumption was not violated.

Normality assumption. This assumption requires the disturbances to be normally distributed. A normality test was run for the model after estimating the regression based on the results shown in Table where the p-values for the model are insignificant suggesting failure to reject the null hypothesis, which postulates that the residual value is normally distributed. Therefore, the data are normally distributed.

Table 3

Press Freedom Index

\begin{tabular}{|c|c|c|c|c|c|c|c|c|c|c|c|c|c|c|c|}
\hline \multirow{2}{*}{ country } & \multicolumn{3}{|c|}{2011} & \multicolumn{3}{|c|}{2012} & \multicolumn{3}{|c|}{2013} & \multicolumn{3}{|c|}{2014} & \multicolumn{3}{|c|}{2015} \\
\hline & Leg & Pol & Eco & Leg & Pol & Eco & Leg & Pol & Eco & Leg & Pol & Eco & Leg & Pol & Eco \\
\hline Ethiopia & 27 & 33 & 18 & 28 & 35 & 18 & 28 & 35 & 19 & 27 & 35 & 19 & 28 & 36 & 19 \\
\hline Djibouti & 24 & 26 & 23 & 24 & 27 & 23 & 24 & 27 & 23 & 24 & 28 & 23 & 24 & 28 & 23 \\
\hline Eritrea & 30 & 40 & 24 & 30 & 40 & 24 & 30 & 40 & 24 & 30 & 40 & 24 & 30 & 40 & 24 \\
\hline Keny & 19 & 18 & 17 & 16 & 19 & 17 & 16 & 20 & 17 & 17 & 23 & 17 & 17 & 23 & 17 \\
\hline Somalia & 27 & 35 & 22 & 27 & 35 & 22 & 27 & 35 & 22 & 26 & 34 & 22 & 25 & 34 & 20 \\
\hline Sudan & 26 & 30 & 22 & 26 & 31 & 21 & 26 & 32 & 22 & 26 & 33 & 22 & 26 & 33 & 22 \\
\hline Uganda & 19 & 21 & 14 & 19 & 24 & 14 & 19 & 22 & 14 & 19 & 24 & 15 & 19 & 23 & 14 \\
\hline
\end{tabular}

Source: Freedom House from 2011-2015

The assumption of homoskedasticity. This assumption requires that the variance of the errors be constant. To check this assumption, the Brusch-Pagan test was conducted for the model. (See Table 4). In this model, there was no problem of heteroskedasticity or the error variance is constant since the $\mathrm{p}$-value is not significant. 
Table 4

Human Development Index

\begin{tabular}{|l|c|c|c|c|c|c|}
\hline \multirow{2}{*}{ Country } & \multicolumn{5}{|c|}{ Year } & \multirow{2}{*}{ Average } \\
\cline { 2 - 7 } & $\mathbf{2 0 1 1}$ & $\mathbf{2 0 1 2}$ & $\mathbf{2 0 1 3}$ & $\mathbf{2 0 1 4}$ & $\mathbf{2 0 1 5}$ & \\
\hline Ethiopia & 0.423 & 0.429 & 0.436 & 0.442 & 0.442 & 0.4344 \\
\hline Kenya & 0.535 & 0.539 & 0.544 & 0.548 & 0.548 & 0.5428 \\
\hline Eritrea & 0.386 & 0.39 & 0.39 & 0.391 & 0.391 & 0.3896 \\
\hline Djibouti & 0.462 & 0.465 & 0.468 & 0.47 & 0.47 & 0.467 \\
\hline Somalia & & & & & & \\
\hline Sudan & 0.468 & 0.472 & 0.473 & 0.479 & 0.479 & 0.4742 \\
\hline Uganda & 0.473 & 0.476 & 0.478 & 0.483 & 0.483 & 0.4786 \\
\hline
\end{tabular}

Source: UNDP Human Development Index

No autocorrelation between the disturbances. It is assumed that the errors are not correlated with one another. If the errors are correlated with one another, it would be stated that they are 'serially correlated'. A test of this assumption was therefore conducted. The first test was the Durbin-Watson which is shown separately in the regression output of the model. The value of the DurbinWatson test is 1.909 , which is close to 2 , demonstrating that autocorrelation does not exist, i.e. the same value does not auto correlate with its previous value.

As summarized in Table 5, the $\mathrm{R}^{2}$ for the model is 66 percent. This indicates that 66 percent of the variation in the Human Development Index was explained by the independent variables used in this study, and only 38 percent of the variance in the Human Development Index is due to other factors that are not included in this study.

The selected variables explain the proportion of variance in the Human Development Index in an orderly manner. The $\mathrm{R}^{2}$ indicates the overall goodnessof-fit of the model developed and tested in the present study. After a modification of the explanatory power of the model, the adjusted $R^{2}$ value is efficiently lowered to 62 percent. This optimal coefficient of determination indicates that 62 percent of the variation in the Eastern African countries' Human Development Index is explained by the explanatory variables in the model. The adjusted $\mathrm{R}^{2}$ measures how well the model fits the data by taking into account the loss of degrees of freedom associated with adding extra variables. Therefore, the model has a high goodness of fit demonstrating a significant degree of predictive accuracy. 
Table 5

Summary of regression output

\begin{tabular}{|l|c|c|c|c|}
\hline \multicolumn{1}{|c|}{ Variables } & Coefficient & Stand. Error & t- statistic & Probability \\
\hline Constant & .485 & .033 & 14.517 & .000 \\
\hline Economic & .006 & .002 & 2.852 & .008 \\
\hline Legal & .009 & .005 & 1.882 & .071 \\
\hline Political & -.011 & .003 & -3.977 & .000 \\
\hline Observations & \multicolumn{2}{|c|}{30} & & \\
\hline $\mathrm{R}^{2}$ & \multicolumn{2}{|c|}{.66} & & \\
\hline Adjusted- $\mathrm{R}^{2}$ & \multicolumn{2}{|c|}{.62} & & \\
\hline F-Statistics & \multicolumn{2}{|c|}{16.56} & & \\
\hline Prob.(F-stat) & \multicolumn{2}{|c|}{.000} & & \\
\hline Durbin- Watson stat & \multicolumn{2}{|c|}{1.909} & & \\
\hline Effect specification & Period fixed & & \\
\hline
\end{tabular}

Source: SPSS regression results based on the data obtained from secondary sources

Note: ***, **, * significant at $1 \%, 5 \%$, and $10 \%$ levels of significance respectively.

In addition, the F-statistic shows the overall significance of variables, or, in other words, the significance of the model slope parameters jointly. The F-statistic of the model is $\mathbf{1 6 . 5 6}$ and the null hypothesis of the model was rejected at the 1 percent significance level. Therefore, the variables of the model are jointly significant. The model adequately describes the data. Hence one can infer from the R squared and F-statistics that the model fits the dataset demonstrating that Press Freedom variables have a significant effect on the Human Development Index.

\section{Press Freedom variables}

Economic environment. As shown in Table 4, the present study found that the economic environment (Econenv) has a positive impact on the Human Development Index $(\mathrm{p}=.008)$. The finding indicates that the value of the economic environment is positively related with the countries' Human Development Index. As discussed in the literature review, economic environment refers to economic pressures on the media, which include the structure of media ownership, the costs of establishing media outlets as well as production and distribution, the selective withholding of state advertising or subsidies, official bias in licensing, and the impact of corruption and bribery on content. Therefore, based on the regression analysis, the economic pressures have a 
strong relationship with or significant impacts on, the Human Development Index of the Eastern African countries. Thus, the hypothesis is supported.

The findings relating to economic pressures support the argument of Novel (2006) that an increase in the value of the economic environment denoting freedom from economic pressure leads to higher Human Development Index. This more succinctly means free press is a crucial factor for the reduction of poverty and enhancement of development. The pertinent findings reported in this study are consistent with prior studies demonstrating that the countries' economic environment has a direct proportional effect on the Human Development Index (Ahrend, 2000). The findings also lend support to the study of Norris (2006) which reports that press freedom especially, and the overall economic environment in particular, has a significant impact on human development. More globally, the associations of the constructs are consistent with those reported in a more recent UNESCO report (Guseva et al., 2008). Bidirectional links are also reported (Alam \& Ali Shah, 2013). Based on a study of 186 countries, Hussain and Haque (2016) also demonstrate a robust association between economic contexts and human development.

In fact, both macroeconomic and microeconomic factors have important bearings on human development through an effect on media development and freedom (Ojo, 2018). In the macroeconomic sphere, the level of unemployment, the rate of inflation and the growth of the economy can all mean a weak media market suggesting an impact on the role of the communication industry as an important contributor to human development. At the microeconomic level media competition may be stiff, especially where the government has big media corporations, which compete with small private companies for ad revenue (Ayeni, 2011). The size of the media market is also an important factor as it means limited diversity in terms of information and perspectives that are vital for development. Demand for communication and culture products may also affect the role of the sector in relevant terms. Coupled with low consumer disposable incomes and high inflation, these factors can impact media business growth and expansion limiting the media's role in human development enhancement.

Legal environment. The result shows that the legal environment (Legenv) has a positive and statistically insignificant impact on the Human Development Index of Eastern African countries $(\mathrm{p}=.071)$. The result seems to show that the laws and regulations that could influence media content do not in this study context exert a significant impact. In addition, the governments' use of press legislation has no significant impact on the Eastern African countries' Human Development Index. Therefore, the hypothesis is not supported. 
However, it would be considered desirable that the legal framework needs to be enabling monitorial or patrol functions relating to officialdom on the behalf of the electorate or citizenry that need media information to make correct electoral decisions based on information on the integrity, performance and promise of a set of politicians holding public office or asking to replace those in power. The legal terrain needs to be plain in matters of administrative desiderata, press registration, licensing and accreditation, unhindered access to informational requests, freedom from undue use of legislation and law enforcement and freedom from psychological oppression of those working to defend society informationally and discursively. The empirical literature generally seems to demonstrate the important functions of legal empowerment in promoting economic development, socio-economic justice, conflict and crime prevention, raising accountability and, and lowering corruption as well as equitable distribution of services (Haggard \& Tiede, 2011; Santos, 2012). More data is needed to show the specific pathways between the legal framework and human development although previous studies have documented mixed results of the association (Berg \& Desai, 2013). More work on definition and consideration of contributory context variables is also in place.

Political environment. The political environment (Polienv) has a significant impact on the Eastern African countries' Human Development Index ( $\mathrm{p}=.000$ ). The political environment explains the variations of the Human Development Index of Eastern African countries with a coefficient of -.011. The result indicates that an increase in the value of the political environment has a negative influence on the Human Development Index of the Eastern African countries and vice versa. This suggests that the degree of political control over the content of news media, which includes access to information and sources, editorial independence, official censorship and self-censorship, the ability of the media to operate freely and without harassment, and the intimidation of journalists by different actors, has a significant impact on the Eastern African countries' Human Development Index. Thus, the hypothesis that there is a relationship between the political environment and the Human Development Index is supported. In further support of the hypothesis there is an evidence base linking respect for civil and political liberties, human rights, and press freedom and a validated inference that journalism is the solution not the problem in political contexts. Journalism can indeed enhance government effectiveness through a forum of transparent communication before official secrecy and repressed issues lead to violence (Guseva et al., 2008).

However, the general relational pattern in regard to the political environment and human development can be far from consistent. Thus, Norris (2006) 
mentioned that Saudi Arabia, Singapore, and Malaysia have good economic conditions, or a high Human Development Index, but their rank in press freedom is a bit lower. Other factors may be at work explaining outlier cases such as the unorthodox empirical evidence of Islam and Osmani (2017) that there may be no causal link between press freedom and human development as their study of Bangladesh seems to demonstrate. However, despite the anomalous observations in a few countries, the political environment is generally considered and empirically demonstrated to be an essential element in boosting human development. Thus, government policies as political factors can affect media businesses through taxation that can further weaken freedom of the press as business survival can be difficult for many newspapers in the face of a small media market further weakened by unsupportive taxation plans (Cagé, 2014). Political environment can also mean new technologies that the independent media need to stay competitive may not be affordable because of high import tariffs while the state media continue to be treated preferentially in relevant spheres. Relatedly potential investors in the media sector may be discouraged from entering the market in view of the considered business risks.

At the level of theory, the link between press freedom and human development is validated in empirical ways taking Sen's (1999) ideas as well as those of others who advanced debates in relevant terms. Sen says that '...p political freedoms and liberties are permissive advantages, and their effectiveness would depend on the how they are exercised' (Sen, 1999) which should include effective media environments inviting and enabling public deliberation of the type advocated by Habermas in his seminal work on the public sphere (Habermas, 1989). The public sphere extends to include public service models of broadcasting that can go a long way in the furtherance of political participation and the betterment of society as singular desiderata the way Sen (1999) sees it fit. The idea of collective capabilities and the liberating effect on the individual are articulated as possibilities of freedom as development.

Contextually the economic and political environments have significant consequences for development as related to communities who can use their expressive capabilities to unleash their potential for emancipatory development. In other words, discursive power in communities can mean better governance outcomes in institutionalized form. It can enhance popular aspirations and lead to progressive societal betterment and civic empowerment bridging the distance between the political elite and the governed. This can mean rejection of regimes that underperform or that have thwarted popular aspirations for freedom and progress. The ideas also relate to economic empowerment as an important base 
to claim more political opportunities and more ability to challenge regimes. Economic independence can mean more choices in the political market and therefore more power for the voter or political consumer.

The idea of justice is also relevant as it fits in with the communication environments and whether they are institutionally supported through liberalizing laws because restrictions can quell and frustrate creativity and innovation that are so much vital for development that has emancipative consequences. The role of the media in enhancing capabilities and functionings can be demonstrated through the development of critical literacies (civic, legal, media, etc.) that people need to be full participants of national development and attain the maximization of their wellbeing. With the media as central institutions, more people empowerment and less government are essential for the freedom enabled by total development, what Sen (1999) seems to advocate.

The implication for Eastern African countries is that the state media in the countries studied are not necessarily about empowering people. As the public interest theory (Djankov et al., 2003) would have it the state media model is paternalistic and has self-seeking designs of promoting the state before and above the people despite its dramaturgical face as the prime promoter of public interest. More innately grassroots media would function in empowering and liberating communities in the ways Sen (Zonk, 2015) would consider ideal strategies in the achievement of development as freedom. In addition, from the angle of modernization theory the attainment of modernization and the attendant civic empowerment conceptually validates the thesis that press freedom and human development are logically correlated. In ways consistent with the present study Mahmood et al. (2011) have empirically demonstrated that press freedom predicts development. In fact, political development is logically tied to economic advancement. (Halperin et al., 2009).

\section{Conclusion}

This study investigated the relationship between Press Freedom and the Human Development Index using six Eastern African countries with a data set covering a five-year period from the year 2011 to 2015. Based on the results of the descriptive statistics, correlation and regression analysis, the following conclusions can be drawn.

Based on the descriptive statistics the average Human Development Index of Eastern African countries is .464. Therefore, the sampled Eastern African countries have a Human Development Index of below 0.5. The sampled Eastern African countries have average values of 19.43, 23.93, and 29.53 of economic, 
legal and political environments respectively (components of the Press Freedom Index). Their values range between minimum values of 14, 16, and 18 and maximum values of 24,30 , and 40 respectively.

The correlation analysis indicates that the legal and political environments have a one percent significant negative relationship with the Human Development Index, whereas the economic environment has a positive correlation with the Human Development Index of the sampled Eastern African countries.

The regression result shows that the economic environment has a significant effect on the Human Development Index. Accordingly, inference can be drawn that the economic environment positively influences the sampled Eastern African countries' Human Development Index.

No statistically significant association was found between the legal environment and the Human Development Index. The political environment negatively and significantly influences the Human Development Index of the Eastern African countries such as Eritrea.

In general, the findings suggest that countries having more press freedom could have better human development levels. Two of the Press Freedom variables empirically support the hypothesis although the level of their significance varies. The legal environment has no significant impact on the Human Development Index among the studied countries probably due to the political and contextual heterogeneity in the region.

The Eastern Africa region is characterized by conflict, instability and poverty that have been further fueling political problems for the countries of the region. The media environment which mirrors the political structure is set to improve but not soon enough and not necessarily for all countries in the region that include new polities such as South Sudan and Eritrea. In Ethiopia there is hope but there are considerable threats of breakup and press freedom is serving a transformative purpose but there are also agendas being served that can make the democratic ideals of tolerance to diversity difficult inviting a fresh cycle of humanitarian crises caused by structural disagreement among the political actors. The mass communication climate is plagued by the tension among centrifugal forces and peripheral pressures. The payoffs of press freedom are not reaped by all in the region that is still struggling with itself. Some countries are sliding in terms of social and economic development and others are deeply immersed in unending cycles of instability. This trend has continuing implications for human development.

Further research using more countries and larger data sets may further explore the press freedom - human development binary. Future studies may 
also consider culture as a factor and other mediating or moderating variables that help to more diagnostically capture the relevant regional picture.

\section{References}

ABDULSAMAD, A. D. (2008). The effect of online journalism on the freedom of the press: The case of Kuwait (Unpublished Thesis). University of Sterling, Scotland, UK.

AHREND, R. (2000). Press freedom, human capital and corruption. Delta Working Paper, 2002-11. Available from: https://papers.ssrn.com/sol3/papers. cfm?abstract_id $=620102$

ALAM, A. \& ALI SHAH, S. Z. (2013). The role of press freedom in economic development: A global perspective. Journal of Media Economics, 26(1), pp. 4-20.

ASANTE, C. E. (1997). Press freedom and development. London, UK, Greenwood Press.

AYENI, O. C. (2011). Advertising in transition: A case study on Nigeria's burgeoning market. In: Advertising in developing and emerging countries: The economic, political and social context, pp.43-56.

BECKER, L. B., VLAD, T., \& NUSSER, N. (2007). An evaluation of press freedom indicators. International Communication Gazette, 69(1), pp. 5-28.

BERG, L. A. \& DESAI, D. (2013). Background paper: Overview on the rule of law and sustainable development for the global dialogue on rule of law and the postdevelopment agenda. Paris, UNDP.

BURROWES, C. P. (1997). Press freedom in Liberia, 1830-1847: The Impact of heterogeneity and modernity. Journalism and Mass Communication Quarterly, 74(2), pp. 331-347.

CAGÉ, J. (2014). The economics of the African media. Oxford Handbook of Africa and Economics, 2. DOI: 10.1093/oxfordhb/9780199687107.013.038

DENNIS, E. E. \& MERRILL, J. C. (1996). Media debates: Issues in mass communication. New York, Longman Publishers.

DJANKOV, S., MCLIESH, C., NENOVA, T., \& SHLEIFER, A. (2003). Who owns the media? The Journal of Law and Economics, 46(2), pp. 341-382.

FLEURBAEY, M. (2002). Development, capabilities, and freedom. Studies in Comparative International Development (SCID), 37(2), pp. 71-77.

FOSTER, J. E. \& HANDY, C. (2008). External capabilities. Oxford. Available from: https://www.ophi.org.uk/wp-content/uploads/OPHI-wp08.pdf

Freedom House (2014). Freedom of the press. Available from: http://www. freedomhouse.org/template.cfm?year $=2014$

GUJARATI, D. N. (2004). Basic econometrics. New York, McGraw-Hill. 
GASPER, D. (2014). Logos, pathos and ethos in Martha C. Nussbaum's capabilities approach to human development. In: F. Comim \& M. Nussbaum, Capabilities, Gender, Equality: Towards Fundamental Entitlements, Cambridge University Press, pp. 96-130.

GUNARATNE, S. A. (2002). Freedom of the press: A world system perspective. Gazette (Leiden, Netherlands), 64(4), pp. 343-369.

GUNARATNE, S. A. (2002). Public diplomacy, global communication and world order: An analysis based on theory of living systems. Current Sociology, 53(5), pp. 749-772.

GUNARATNE, S. A. (2005). The Dao of the press: A humanocentric theory. New Jersey, Hampton Press.

GUSEVA, M., NAKAA, M., NOVEL, A., PEKKALA, K., SOUBEROU, B., \& STOULI, K. (2008). Press freedom and development. Paris, UNESCO.

HABERMAS, J. (1989). The structural transformation of the public sphere: An inquiry into a category of bourgeois society. Polity, Cambridge.

HACHTEN, W. A. (2005). The troubles of journalism. New Jersey, Lawrence Erlbaum Associates, Inc.

HAGGARD, S. \& TIEDE, L. (2011). The rule of law and economic growth: Where are we? World development, 39(5), pp. 673-685.

HALPERIN, M., SIEGLE, J., \& WEINSTEIN, M. (2009). The democracy advantage: How democracies promote prosperity and peace. Routledge.

HOFFMANN, J. P. (2010). Linear regression analysis: Applications and assumptions. Brigham Young University, Provo.

HUSSAIN, M. E. AND HAQUE, M. (2016). Impact of economic freedom on the growth rate: A panel data analysis. Economies, 4(2). DOI:10.3390/ economies 4020005

ISLAM, A. \& OSMANI, A. G. (2017). Does press freedom cause human development? Examining Bangladesh. Media Asia, 44(3-4), pp. 142-148.

JACOBSON, T. L. (2016). Amartya Sen's capabilities approach and communication for development and social change. Journal of Communication, 66(5), pp. 789-810.

KAUFMAN, A. (2006a). Capabilities and freedom. Journal of Political Philosophy, 14(3), pp. 289-300.

KELLEY, D. \& DONWAY, R. (1990). Liberalism and free speech. In: J. Lichtenberg, Democracy and the mass media, Cambridge University Press.

MAHMOOD, R., TRAN, H. \& DU, Y. (2011). Linking measures of global press freedom to development and culture: Implications from a comparative analysis. International Journal of Communication, 5, pp. 170-191. 
MATUNHU, J. (2011). A critique of modernization and dependency theories in Africa: Critical assessment. African journal of History and Culture, 3(5), pp. 65-72.

MERRILL, J. C. (2000). Social stability and harmony: a new mission for the press? Asian Journal of Communication, 10(2), pp. 33-52.

NAM, S. \& OH, I. (1973). Press freedom: Function of subsystem autonomy, antithesis of development. Journalism Quarterly, 50, pp. 744-750.

NORRIS, P. (2006). The role of free press in promoting democratization, good governance and human development. In: Paper for the Midwest Political Science Association Annual Meeting, World Press Freedom Day, April 20-22, 2006. Chicago, IL, Palmer House.

NOVEL, A. S. (2006). Press freedom and poverty (UNESCO-CPHS research project). Paris, UNESCO.

OJO, T. (2018). Media ownership and market structures: Banes of news media sustainability in Nigeria? Media, Culture \& Society, 40(8), pp. 1270-1280.

ROBEYNS, I. (2005). The capability approach: A theoretical survey. Journal of Human Development, 6(1), pp. 93-117.

ROGERS, E. M. (1997). Press freedom and development: A research guide and selected bibliography. Westport, Greenwood Publishing Group.

SANTOS, A. (2012). The World Bank's uses of the 'rule of law' promise in economic development. In: D. Trubek \& A. Santos, The new law and economic development: A critical appraisal, Cambridge University Press, pp. 253-300.

SEN, A. K. (1999). Development as freedom. Oxford University Press.

STREETEN, P. (1994). Human development: Means and ends. Human Development, 84(2), pp. 232-237.

UNDP (1990). Human Development Report 1990. NY, Oxford University Press.

UNESCO (2008). Press freedom and development. Available from: www. unesco.org/webworld/

United Nations Development Programme (1997). Human Development Report 1997.

WEAVER, D. H. (1977). The press and government restriction: Across-national study over time. Gazette, 23, pp. 152-170.

ZINK, J. (2015). Amartya Sen and the media. Real-World Economics Review, 72, pp. 69-95. 